Finisterra, XXXVI, 72, 2001, pp. 149-156

\title{
PENSAR A PAISAGEM. Da aventura interior ao campo da História
}

\author{
Viriato SOROMENHO-MARQUes ${ }^{1}$
}

A paisagem enquanto objecto da reflexão filosófica pode ser considerada como um dos modos mais recentes da filosofia da natureza. É difícil, e talvez inutilmente arriscado, procurar uma excessiva precisão no que concerne ao nascimento de uma moderna reflexão sobre a paisagem. Julgo, contudo, que as características fundamentais da meditação sobre a paisagem são inseparáveis do processo de constituição do sistema de valores, saberes e instituições da sociedade tecnocientífica que nos serve de inquietante pátria civilizacional.

Quando na primeira metade do século XVIII Albrecht von Haller publicou o seu poema Die Alpen, celebrizando a beleza das grandes montanhas e o benefício moral para os seres humanos do convívio com elas, estava dado o mote que seria alargado e aprofundado pelo movimento romântico na sua variedade de escolas e tendências. $\mathrm{O}$ mesmo movimento da modernidade, que nas filosofias de Bacon e Descartes tinha construído as suas poderosas armas de guerra para a dominação tecnológica da natureza, transformada - pelo menos nos grandes contornos da nova ontologia cartesiana - numa res extensa nua de espiritualidade, começava, agora, com o advento do surto das grandes metrópoles e dos primeiros odores pestilentos da combustão do carvão, a procurar, através da categoria e da temática da paisagem, restaurar uma relação mais harmoniosa com a natureza e os seus mistérios aparentemente em vias de desaparecimento.

A reflexão sobre a paisagem, na variedade dos seus matizes e perspectivas, e em termos muito gerais, poderá considerar-se como uma acompanhante crítica do processo de «desencantamento do mundo» (die Entzauberung der Welt), recorrendo à acutilante fórmula com que Max Weber descrevia o seu e o nosso tempos. No essencial gostaria, neste brevíssimo ensaio, de destacar duas figuras da reflexão sobre a paisagem. Em ambos os casos o que está em causa é a procura do autoconhecimento e da identidade. Na primeira figura, a contemplação da paisagem serve de veículo e de meio para a experiência interior. Tratase de uma espécie de imitação moderna da labuta interior dos místicos medievais, só que a transcendência visada pelo comércio solitário com as montanhas, os bosques ou as praias desertas não coincide já com os predicados

\footnotetext{
1 Professor Associado com Agregação, Departamento de Filosofia da Universidade de Lisboa, E-mail: vsmarques@mail.telepac.pt
} 
de uma divindade revelada. Na segunda figura, os elementos marcantes da paisagem são simbolicamente destacados para a elaboração de uma grande e épica viagem. Só que desta vez, a aventura já não é pessoal, mas colectiva. O destino que a paisagem ajuda a iluminar já não tem como sujeito os indivíduos, mas sim os povos e a humanidade no seu conjunto.

\title{
I. A PAISAGEM NA AVENTURA INTERIOR
}

Foi Heinrich Heine quem mais claramente estabeleceu como uma das maiores grandezas da filosofia kantiana o facto de ela ter sido responsável pela morte teórica de Deus. A separação entre fé e saber, a demonstração de que as tradicionais provas especulativas da existência de Deus não passavam de inevitáveis, mas erróneos e materialmente infundados devaneios dialécticos, abrem um novo campo para a filosofia no seu conjunto, e para o tema da natureza como paisagem, em particular.

Em 1788, no final da sua segunda grande obra maior do período crítico, a Crítica da Razão Prática, escrevia Kant:

\begin{abstract}
«Duas coisas enchem o espírito duma admiração e duma veneração sempre novas e crescentes, quanto mais frequente e incessantemente a reflexão com isso se ocupa: o céu estrelado por cima de mim e a lei moral em mim. (...) O primeiro panorama de uma quantidade inumerável de mundos destrói por assim dizer a minha importância como criatura animal, que deve devolver a matéria da qual se formou ao planeta (um simples ponto no universo) depois de ter sido durante um certo período de tempo (não se sabe como) dotado de força vital. O segundo, pelo contrário, eleva infinitamente o meu valor como uma inteligência, através da minha personalidade, na qual a lei moral me revela uma vida independente da animalidade e mesmo de todo o mundo sensível [...]» (KANT, KpV, Ak.V, pp. 161-2) ${ }^{2}$.
\end{abstract}

Nesta meditação fascinante, Kant coloca a condição humana no vórtice das suas incertezas e desafios fundamentais. À semelhança de Pascal, Kant recusava-se a ver na paisagem cósmica dos «espaços infinitos» um símile da confiada infinitude divina. Contudo, em vez do silêncio atemorizador que essa contemplação causava a Pascal, Kant - que para além de gigantesco filósofo, foi também um astrónomo muito original - sentia na visão da rede inumerável de mundos e sistemas de mundos uma "veneração» (Ehrfurcht) aparentemente análoga à experimentada pela vivência da dimensão ética interior.

Na verdade, a condição humana pertence simultânea e inseparavelmente a esses dois reinos: à natureza, determinada pelas formas do espaço e do tempo, que na ideia de mundo como totalidade atinge a sua universalidade e

2 Tradução do autor. 
limite máximos; à ideia de um mundo possível pela liberdade, cuja semente universal se encontra na universalidade da lei moral, que nos transporta para uma filosofia do primado da razão prática e da compreensão da própria racionalidade como construção e tarefa infinitas. Só numa leitura superficial surpreenderíamos em Kant uma qualquer tentativa de reduzir a natureza ao estatuto de etapa superada ou mero obstáculo a abater. Pelo contrário, no estudo kantiano do domínio estético, vislumbramos no pensador de Königsberg uma enorme preocupação por devolver à natureza uma profundidade e uma densidade próprias, que, uma leitura redutora da sua filosofia do interesse meramente teórico não nos permitiria descortinar. Como muito bem escreve Leonel Ribeiro dos Santos: «O sentimento estético é a manifestação da condição simultaneamente animal (sensível) e espiritual do homem [...] A experiência estética e teleológica permitem assim aceder a uma relação com a Natureza que é já não a da posse, a do domínio instrumental e da violência, nem apenas a do respeito e do temor, mas a da mútua amabilidade, a do livre favor, a da espontânea gratuidade e doação» (SANTOS, 2001: 190-192).

A meditação kantiana sobre o belo e a finalidade na Natureza abre-nos o horizonte para os fundamentos de uma moderna filosofia da paisagem. Os seus dois alicerces estruturantes estão já presentes em Kant e podem enunciar-se do seguinte modo: por um lado, a natureza não é simples matéria-prima, mera entidade passiva para a plástica operante de uma racionalidade instrumental tecnocientífica; por outro lado, a espontaneidade própria da natureza, que se concretiza na graciosidade das formas paisagísticas, não é reconduzível ao discurso apologético de uma racionalidade divina. A filosofia da paisagem exige que aquilo que contemplamos no horizonte não seja redutível a objecto passivo seja da técnica humana, seja da inteligência divina. Pensar a paisagem obriga a um exercício de atenção renovado, ao esforço de um olhar sem preconceito, de uma audição fina dos ventos do mundo, em busca de uma oculta linguagem propícia a secretos encontros.

Nas rêveries passeantes de Rousseau, nos périplos de autodescoberta juvenil de Byron e Schopenhauer, nos diários de viagem de Victor Hugo, na ascese ontológica da paisagem, patente na obra desse caminhante incansável que foi Nietzsche, encontramos sempre a presença dessa dupla negativa. Se queremos que a contemplação da paisagem seja um palco para o teatro da aventura interior, então não podemos deixar que a natureza se reduza à terra que o arado desbrava, nem ao mero resultado da acção de um Deus revelado positivamente na história, disciplinado numa teologia, e ritualizado num culto.

Ao experimentar a natureza como paisagem, como uma tela imensa sem autor identificável, o pensamento da paisagem conduz-nos a uma nova perspectiva sobre nós próprios e a uma diversa interpretação das relações entre o pensamento e os seus objectos. Uma das propostas que podemos encontrar no horizonte da filosofia da paisagem é a do 'transcendentalismo' do pensador norte-americano Emerson. Ele sugere que a verdadeira essência da humani- 
dade e da natureza só podem ser captadas na relação íntima entre ambas, através da mediação do pensamento. Escutemos Emerson:

«A natureza é a encarnação de um pensamento, que regressa ao pensamento, de novo, do mesmo modo que o gelo se transforma em água e gás. O mundo é a precipitação da mente, e a sua essência volátil está permanentemente a escapar-se, uma e outra vez, para o estado de pensamento livre. Daqui deriva a virtude e pungência da influência sobre a mente dos objectos naturais, sejam inorgânicos ou orgânicos. O homem aprisionado, o homem cristalizado, o homem vegetativo fala com o homem em pessoa» (EMERSON, 1994: 400-401) ${ }^{3}$.

Este pensamento livre, poroso e transversal de que nos fala Emerson, não se confunde com o exercício de um entendimento calculador, mas antes com o que poderíamos designar como a eclosão de uma dimensão espiritual de comunhão e unidade, incapaz de ser reduzida à esfera do quantitativo e do formal. Na mesma linha de orientação se situa o nosso Teixeira de Pascoaes:

«Avisto sempre, na paisagem, uma forma concreta ou revelada e outra a revelar-se vagamente. É assim o nosso rosto: um desenho e um esboço, a imagem definida e a indefinir-se numa expressão misteriosa [...] Nunca me conformei com um conceito puramente científico da Existência, ou aritméticogeométrico, quantitativo-extensivo. A existência não cabe numa balança ou entre os ponteiros dum compasso.» (PAscoAes, 1993: 2).

O pensar da paisagem implica também a presença de um juízo crítico sobre o poder humano de a modelar e transformar. Estamos, contudo, longe da tese de um quietismo absoluto, na medida em que a acção humana pode inspirar-se na implementação de formas e modelos inspirados pela procura da beleza e pelo desejo de afirmar uma harmonia entre a obra humana e a sua raiz e envolvente naturais, como é o caso do projecto de arquitectura paisagista que encontramos, por exemplo, nos trabalhos e na reflexão de Francisco Caldeira Cabral (CABRAL, 1993: 26). No entanto, invariavelmente, os filósofos da paisagem são críticos do espectáculo das cidades, pela atrofia do espaço, pelo exílio das forças naturais, pela concentração excessiva e ruidosa de humanidade.

Ouçamos a este propósito, de novo, Emerson:

«As cidades não conferem espaço suficiente aos sentidos humanos. Nós saímos de dia e de noite para alimentar os olhos no horizonte. Eles necessitam tanto de largueza, como nós precisamos de água para o banho» (EMERSON, 1994: 382) ${ }^{4}$.

3 Tradução do autor.

4 Tradução do autor. 
Num outro ângulo, deparamos com o elogio da solidão efectuado por John Stuart Mill, que nos serve de apoio tanto para o repensar da cidade como para as contemporâneas políticas de conservação da Natureza e protecção da paisagem, onde a experiência da solidão e do recolhimento se transformam em valores psicológicos e morais, a colocar ao lado da necessidade de preservar as espécies e os habitats em perigo de extinção:

«Um mundo do qual a solidão tivesse sido banida constituiria um ideal bem pobre. A solidão, no sentido de estarmos sós com frequência, é essencial para qualquer nível de meditação ou de carácter; a solidão, na presença da beleza e da grandiosidade da natureza é o berço dos pensamentos e das aspirações benéficas não só para o indivíduo como também para a sociedade.» (MILL, 1970: 116) ${ }^{5}$.

Não nos pode surpreender, portanto a ocorrência cultural de uma espécie de «regresso à natureza», levado, por vezes, a formas radicais, como foi o caso do isolamento de Thoreau, durante dois anos, num bosque nas vizinhanças do lago Walden, perto de Concord, no Massachusetts. Na obra que esse influente pensador norte-americano dedicou ao seu exílio voluntário numa paisagem, nessa altura, ainda natural, as razões apresentadas apontam para um dos desideratos patentes noutras meditações filosóficas sobre a paisagem, a saber, o desejo por uma vida autêntica e plena:

«Eu fui para os bosques porque eu queria viver com intenção e propósito, enfrentar apenas os factos essenciais da vida [...] Eu queria viver profundamente e chupar todo o tutano da vida [...] Não somos nós que montamos o caminho-de-ferro. É ele que nos monta.» (THOREAU, 1986: 135-136) ${ }^{6}$.

\section{A PAISAGEM E O CAMPO DA HISTÓRIA}

Outra perspectiva no âmbito do que, de modo muito lato, podemos designar como reflexão sobre a paisagem, consiste nas tentativas para construir uma narrativa da história universal, tanto do seu passado como do seu futuro, inspirando-se na ampliação, até ao assumir de uma dimensão epocal, dos elementos estruturantes da paisagem. Trata-se, em grande medida, do resultado do cruzamento, ocorrido também no século XVIII, entre o surgimento da filosofia da história e a fundação da geografia moderna.

Vou limitar-me, apenas, a dois exemplos. O primeiro encontra-se nas lições dedicadas por Hegel ao tema da filosofia da história. O que torna esse livro interessante não é, evidentemente, o tratar-se de uma busca pelos princípios

5 Tradução do autor.

6 Tradução do autor. 
filosóficos necessários à compreensão da história. Nessa medida, Hegel segue uma linha de rumo onde pontificam autores como Voltaire ou Herder. A novidade consiste no acentuar dos factores e elementos geográficos e paisagísticos nos contornos essenciais dessa reflexão sobre a história. Para trás Hegel tinha Montesquieu. Para diante, o autor alemão não ficará sozinho. $\mathrm{O}$ aparecimento, num contexto mais geo-político e geo-estratégico, de autores como o almirante francês Castex e o filósofo da geografia Ernst Kapp, revelam que a presença de elementos definidores da paisagem na determinação histórico-filosófica do destino da humanidade continuará a atrair vocações intelectuais relevantes.

A importância da geografia e da paisagem para o curso da história universal e para a construção dos sujeitos que a animam, o que no entender de Hegel é o lugar que deve ser ocupado pelo "espírito dos povos», surge sublinhado com clareza no longo excerto que traduzimos da obra do autor germânico. O facto de Portugal ser o centro dessa meditação de Hegel talvez estimule o leitor a ser benevolente para com a invulgar extensão desta citação.

Escutemos Hegel:

«[...] É em Portugal que os rios de Espanha encontram a sua saída para o mar. Dever-se-ia crer que, tendo a Espanha rios, deveria também ter uma relação com o mar; mas, essa relação foi especialmente desenvolvida por Portugal.

$\mathrm{O}$ mar fundamenta de um modo geral um tipo específico de vida. O elemento indeterminado dá-nos a representação do ilimitado e do infinito, e o homem sentindo-se no interior desse infinito encoraja-se para ultrapassar o limitado. O mar é o que em si próprio não tem fronteiras, e não suporta qualquer calma delimitação em cidades, como sucede em terra firme. A terra, a planície fluvial, fixa os homens ao solo; devido a isso ele tomba numa grande quantidade de dependências. Mas o mar condu-lo para além desse círculo limitado. $\mathrm{O}$ mar desperta-lhe a coragem; convida o homem à conquista e ao saque, mas também ao ganho e à aquisição [...] Aqueles que navegam no mar, querem e podem também ganhar e adquirir; mas o meio utilizado torna-se imediatamente no contrário daquilo por que havia sido escolhido, nomeadamente em perigo; invertendo-se de tal forma, que eles correm o risco de perder os seus bens e a sua vida. Através disto [...] ganha o indivíduo a consciência de uma maior liberdade e independência. É isto que faz o ganho e actividade elevarem-se acima de si próprias, tornando-se em algo de corajoso e nobre. O mar desperta a coragem; aqueles que o experimentam para ganhar a vida e a riqueza devem procurar o seu sustento através da mediação do perigo, eles devem ser corajosos, arriscar e desprezar a vida e a riqueza [...]. O mar acorda também a astúcia, porque o homem tem de combater com um elemento, que parece submeter-se calmamente a tudo, adaptar-se a todas a formas e que, no entanto, é funesto. A coragem encontra-se aqui essencialmente ligada à inteligência, que é a suprema astúcia. Assim, a coragem perante o mar deve igualmente ser astúcia, porque ela tem de enfrentar o mais ardiloso, o mais inseguro e o menos fiável dos elementos [...]» (Hegel, 1968: 197-198) ${ }^{7}$.

7 Tradução do autor. 
O segundo exemplo que gostaria de convocar para este estudo, é o de uma brevíssima obra da autoria do filósofo da política, Carl Schmitt, escrita em 1942, no ponto intermédio da segunda hecatombe bélica da século passado. O interesse desta obra, na minha perspectiva, tem duas raízes. A primeira situa-se no facto de o seu princípio operatório fundamental, o conceito de «revolução espacial» (Raumrevolution) conduzir o seu autor a uma teoria do "caminho particular» (Sonderweg) alemão em que se anuncia a própria inevitabilidade da derrota da Alemanha, em confronto com as duas maiores potências navais do mundo, a Grã-Bretanha e os Estados Unidos. A segunda razão do interesse deste ensaio, consiste na perspectiva de reordenamento hermenêutico da nossa ideia de Modernidade, conduzindo o pensador a um exercício antecipativo, uma espécie de profetismo, em que se podem detectar sinais visíveis das inquietações da nossa contemporaneidade em trânsito milenar.

Para Schmitt a dinâmica da história humana vai da terra em direcção ao mar. A Terra é o elemento a que o homem está destinado, mas o Mar é o elemento da sua liberdade, da sua "possibilidade de um renascimento» (ScHMITT, 1981: 14). Toda a civilização humana necessita de água para subsistir. Por isso Schmitt recorda a trilogia epocal, proposta por Kapp, que nos fala do périplo que vai das culturas fluviais, passando pelas culturas talassocráticas, limitadas a mares fechados, como o Mediterrâneo, em direcção às culturas oceânicas. Só nestas, o elemento hídrico ganha independência e se pode contrapor verdadeiramente ao elemento terrestre.

No entanto, uma escrita que não poderia ignorar os flagelos da guerra aérea, então em plena expansão, não poderia também limitar-se aos elementos estruturantes da terra e da água. Nesse sentido escreve Schmitt: «De acordo com uma antiga doutrina o conjunto da história universal não é mais do que uma viagem através dos quatro elementos» (Sснмiтt, 1981: 105). Por outras palavras: depois de uma longa estada de inúmeros milénios sobre a Terra, a humanidade teria lançado as velas para uma aventura oceânica secular no Mar, à qual se sucederia uma rapidíssima ascensão com armas e bagagens, em direcção ao Ar, para tudo se concluir, provavelmente, numa medida cronológica ainda mais lacónica, no elemento que resta, o Fogo...

Desta forma, seja na vertente da demanda interior pela identidade pessoal, seja na interpretação dos sinais proféticos relativos ao sentido do porvir da história universal, a paisagem forneceu sempre à filosofia dos modernos matéria e meios expressivos para a articulação de uma reflexão sobre a questão dos fundamentos e dos limites, que sempre constituíram o objecto e a vocação da filosofia. 


\section{BIBLIOGRAFIA}

Cabral, Francisco Caldeira (1993) - Fundamentos da Arquitectura Paisagista, Instituto de Conservação da Natureza, Lisboa.

Emerson, Ralph Waldo (1994) - Nature and Other Writings, Boston \& London, Shambhala (editado por P. Turner).

Hegel (1968) - Die Vernunft in der Geschichte, Vorlesungen über die Philosophie der Weltgeschichte, vol. I, Felix Meiner, Hamburg.

KANT (1902 ss.) - Kritik der praktischen Vernunft, Gesammelte Schriften, vol V, Preussische Akademie der Wissenschaften, Berlin.

MiLL, John Stuart (1970) - Principles of Political Economy, Penguin Books, London.

Pascoaes, Teixeira de (1993) - O Homem Universal e Outros Escritos, Assírio \& Alvim, Lisboa.

SAntos, Leonel Ribeiro dos (2001) - Kant e o Regresso à Natureza como Paradigma Estético, Natureza e Ambiente: Representações na Cultura Portuguesa, C. BECKERT (ed.), Centro de Filosofia da Universidade de Lisboa, Lisboa: 169-193.

Sснмітт, Carl Schmitt (1981)-Land und Meer. Eine Weltgeschichtliche Betrachtung [1942], Hohenheim Verlag, Köln-Lövenich.

Thoreau, Henry David (1986) - Walden and Civil Disobedience, Penguin Books, New York. 